\title{
Rehabilitation and outcome after severe head injury
}

\author{
R Scott-Jupp, N Marlow, N Seddon, L Rosenbloom
}

\begin{abstract}
After severe head injury, many children continue to experience major cognitive and behavioural problems and consequent educational difficulties, even after good physical recovery. Forty three children referred to the regional multidisciplinary head injury rehabilitation team are described. The clinical outcome at a median interval of 13 months after injury showed that $18(42 \%)$ had persistent neurological impairment and $15(35 \%)$ had an identified need for special educational support. Thirty seven children were further assessed for psychiatric morbidity, cognitive impairment, and classroom performance. Rutter behavioural questionnaires were sent to parents and teachers of head injured index cases and classmate controls matched for age and sex. Index parents scored their children significantly worse in both 'health' and 'habits' and more cases than controls had scores suggesting a psychiatric disorder. Teachers scored index cases significantly worse for five of the traits questioned, but discriminated cases from controls less decisively than parents. Index cases were significantly disadvantaged on teachers' assessments of classroom skills and performance. A need for improved support and training of staff who teach head injured children was identified.
\end{abstract}

Head injury is a major cause of acquired neurological impairment in childhood. The spectrum of injury is wide and there is frequently a need for prolonged hospitalisation. The scope for recovery is equally wide and may take place over some considerable time. ${ }^{1}$ Recovery may be improved by early intervention and good rehabilitation facilities, ${ }^{2}$ but in the UK the adequacy of the current service provision for children has been questioned. ${ }^{3}$ Few units have reported long term data. Since 1985, in the Royal Liverpool Children's Hospital at Alder Hey, a multidisciplinary team has attempted to optimise recovery and rehabilitation after severe head injury. The work of this team has steadily grown in parallel with an awareness of the problems faced by these children in both the short and medium term. This paper describes the outcome for children so managed from clinical, behavioural and educational standpoints, to provide data against which further service developments may be assessed.

\section{Methods}

POPULATION

Between September 1985 and February 1989, children with severe head trauma within the Mersey region and adjoining districts were referred to the neurosurgical unit at Walton Hospital or to one of the Royal Liverpool Children's Hospitals (RLCH) at Myrtle Street or Alder Hey. Neurosurgeons and paediatricians at these sites referred children with posttraumatic neuromotor impairment or delay in recovery for assessment by the head injury team. Children were transferred to RLCH Alder Hey for rehabilitation.

\section{THE HEAD INJURY TEAM}

The team was based around the Child Development Centre and comprised representatives from all rehabilitative specialties: medical, physiotherapy, occupational therapy, speech therapy, educational psychology, social work, nursing, and education. All had experience in paediatric rehabilitation and a special interest in head injury. The team was supervised by the senior registrar attached to the regional paediatric neurology unit. Patients were referred directly to the medical team and assessments and therapy organised subsequently as appropriate, as the child recovered. The motor, speech, and educational status of all children were assessed by team members as soon as possible after referral, with the involvement of other specialists as deemed necessary. The team took care to support and inform the families of the injured and to involve them fully in the rehabilitation process. The progress of each child, as hospital inpatient or outpatient, was monitored at team meetings every two weeks attended by representatives from each specialty. Nursing staff from each child's ward, and community based professionals, were also invited to attend as appropriate. Contact was maintained with each child after discharge through the minimum number of visits necessary. An early appreciation of the need for slow reintegration within the mainstream educational system resulted in many children attending the Alder Hey Hospital School on a day patient basis, until there was sufficient recovery to allow return to their mainstream school or completion of statements of need for special educational provision. The importance of medical involvement decreased with time but the senior registrar adopted a facilitative role when no further acute paediatric input was required.

FOLLOW UP DATA

All notes were reviewed in the summer of 1989

and clinical data abstracted for analysis. The
Leicester Royal Building,

Leicester LE2 7LX.

Accepted 10 October 1991 
parents of each child of school age, for whom six months had elapsed since the injury, were circulated with a Rutter behavioural questionnaire ${ }^{4}$ and permission sought to obtain information from the child's school. The head teacher of each school was approached and asked to select, from the index child's class, the child of the same sex with the nearest birthdate to the index child. The parents of these classmate controls were approached in turn and asked to complete a behavioural questionnaire (Rutter $A(2)$ ) and for permission to obtain information from the school. Teachers then completed behavioural questionnaires (Rutter $B(2)$ ) for both cases and controls, which were supplemented with 10 items from the Conners' hyperactivity scale. ${ }^{5}$ Teachers also provided further details concerning the progress of each child, and for the index children completed a questionnaire detailing the information they had received concerning the child and their opinion of the adequacy of facilities available for such children at their school.

Questionnaires were scored as recommended and the alternative assessment of emotional or conduct disorders used. Data were encoded for analysis using the SPSS-PC+ statistical software package. The Mann-Whitney $U$ test and $\chi^{2}$ statistics were used to compare population and frequency data as appropriate, and the SPSS discriminant and regression options were used for multivariate analysis.

\section{Results}

\section{PATIENT DATA}

Between September 1985 and March 1989, 43 children were referred for rehabilitation at a median age of $9 \cdot 4$ years (range $2 \cdot 9-15.0$ years). There was an excess of males $(32 ; 74 \%)$ and three children were known to have pre-existing disability. Eighteen were admitted directly to RLCH Alder Hey, and three directly to the regional neurosurgical centre at Walton; the remainder were referred from centres without paediatric intensive care facilities. The causes of neurological injury and associated trauma are shown in table 1. Most of the children were pedestrian victims of road traffic accidents. Fourteen children had skull fractures: of these, 11 were vault fractures of which two were

Table 1 Clinical data on 43 patients referred to the head injury team

\begin{tabular}{lr}
\hline & $\begin{array}{l}\text { No }(\%) \\
\text { of patients }\end{array}$ \\
\hline Source of brain injury & \\
All road traffic accident & $36(84)$ \\
$\quad$ Child as pedestrian & $33(77)$ \\
Fall from tree/roof & $5(12)$ \\
Other causes & $2(5)$ \\
Other significant injuries & $26(60)$ \\
Orthopaedic injuries & $23(53)$ \\
Surgical procedure(s) required & $15(35)$ \\
Tracheostomy & $6(14)$ \\
Craniotomy & $2(5)$ \\
Debridement/suturing & $3(7)$ \\
Fracture reduction & $2(5)$ \\
Intracranial pressure monitor & $2(5)$ \\
Ventricular shunt & $1(2)$ \\
Laparotomy & $1(2)$ \\
Embolisation of traumatic arteriovenous fistula & $1(2)$ \\
Mechanical ventilation & $22(51)$ \\
Seizures (within seven days of injury) & $13(30)$ \\
\hline
\end{tabular}

depressed, one compound, and one comminuted. There were two facial and one basal fracture. Computed tomography was performed in all children. Fourteen (33\%) were normal, while $15(35 \%)$ had intracerebral haemorrhage, $14(33 \%)$ cerebral contusions, and $12(28 \%)$ evidence of cerebral oedema. Fifteen children required surgery and 13 had seizures during the seven days after head injury. Twenty two $(51 \%)$ received mechanical ventilation for a median time of 60 days (range 2-104 days).

The timing of referral to the head injury team depended upon the child's progress and accessibility, but in most cases contact with team members was made within the first one to two weeks after injury. All children were seen by the physiotherapy, occupational therapy, and educational services. Five also required inpatient speech therapy, and six psychological assessment, usually by the educational psychologist attached to the team. At the time of data collection three remained as inpatients. For the remainder the median admission lasted 60 days (range 5-300 days).

\section{CLINICAL OUTCOME}

Clinical problems evident at discharge are shown in table 2, together with the frequency of the same findings at the last reported follow up examination after a median interval of 13 months (range 2-34). Post-traumatic fits were uncommon. No clinical predictors of outcome were observed after univariate or multivariate analysis. However, 13 of the $18(72 \%)$ children with motor impairment at follow up had received mechanical ventilation compared to eight of the 25 (32\%) children who were unimpaired $(p=0.009)$. The frequency of overt impairments deceased with time, but a very significant proportion of children had residual impairments of motor function $(18 ; 42 \%)$ or behaviour $(16$; $37 \%)$ and $15(35 \%)$ were receiving special educational provision. The high frequency of behavioural and educational sequelae prompted the comparative study which follows

\section{BEHAVIOURAL OUTCOME}

Information on 37 index children and controls was requested from parents and teachers, at a median of 23.7 months after injury (range 6-47 months). Thirty two index and 33 control parents replied ( $86 \%$ and $89 \%$, respectively) and school data were returned for 31 index and 29 control children (84\% and $78 \%)$.

Table 2 Impairments among 43 head injured children at discharge and at last medical follow up (2-34 months after discharge)

\begin{tabular}{|c|c|c|}
\hline & $\begin{array}{l}\text { No (\%) } \\
\text { at discharge }\end{array}$ & $\begin{array}{l}\text { No (\%) } \\
\text { at follow up }\end{array}$ \\
\hline $\begin{array}{l}\text { Abnormal neurological signs } \\
\text { Quadriplegia } \\
\text { Hemiplegia } \\
\text { Diplegia } \\
\text { Dyskinesia } \\
\text { Cranial nerve palsies } \\
\text { Seizures } \\
\text { Receiving anticonvulsants } \\
\text { Speech disorder } \\
\text { Need for special educational } \\
\text { support identified }\end{array}$ & $\begin{array}{l}2(5) \\
11(26) \\
8(19) \\
5(12) \\
2(5) \\
0 \\
8(19) \\
8(19) \\
30(70)\end{array}$ & $\begin{array}{ll}2 & (5) \\
9 & (21) \\
5 & (12) \\
3 & (7) \\
0 & \\
1 & (2) \\
4 & (9) \\
1 & (2) \\
15 & (35)\end{array}$ \\
\hline
\end{tabular}


Table 3 Results of Rutter behavioural questionnaires

\begin{tabular}{|c|c|c|c|}
\hline & Index children & Controls & $p$ Value \\
\hline $\begin{array}{l}\text { Median age in months (range) } \\
\text { Parents' questionnaire }\end{array}$ & $\begin{array}{l}141(49-205) \\
n=32 \\
\text { Median (iqr) }\end{array}$ & $\begin{array}{l}142(58-198) \\
n=33 \\
\text { Median (iqr) }\end{array}$ & \\
\hline $\begin{array}{l}\text { Total characteristics scored per child } \\
\text { Health } \\
\text { Habits }\end{array}$ & $\begin{array}{l}8 \cdot 5(4-15) \\
3(2-6 \cdot 5) \\
3(2-4)\end{array}$ & $\begin{array}{l}4(2-8) \\
1(1-2) \\
2(1-2)\end{array}$ & $\begin{array}{l}0 \cdot 015 \\
0 \cdot 0002 \\
0 \cdot 0008\end{array}$ \\
\hline $\begin{array}{l}\text { No of children with } \\
\text { psychiatric disorder }\end{array}$ & $9(28 \%)$ & $2(6 \%)$ & $0 \cdot 018^{\sharp}$ \\
\hline $\begin{array}{l}\text { Teachers' questionnaire } \\
\text { Total characteristics scored per child } \\
\text { Emotional score } \\
\text { Conduct score } \\
\text { Hyperactivity rating } \\
\text { Conners' hyperactivity items }\end{array}$ & $\begin{array}{l}n=31 \\
7(2 \cdot 5-11 \cdot 5) \\
2 \cdot 5(0-5 \cdot 5) \\
2(0-4) \\
3 \cdot 5(1-6) \\
8(2 \cdot 5-12 \cdot 5)\end{array}$ & $\begin{array}{l}n=29 \\
1(0-7 \cdot 5) \\
1(0-2) \\
0(0-3) \\
0 \cdot 5(0-4) \\
2(0 \cdot 5-5)\end{array}$ & $\begin{array}{l}0 \cdot 024 \\
0 \cdot 02 \\
0 \cdot 12 \\
0 \cdot 015 \\
0 \cdot 003\end{array}$ \\
\hline $\begin{array}{l}\text { No of children with } \\
\text { psychiatric disorder }\end{array}$ & $11(35 \%)$ & $6(21 \%)$ & $0 \cdot 20^{*}$ \\
\hline
\end{tabular}

Measures compared using Mann-Whitney $U$ test or $\chi^{2}$ test ( $\left.{ }^{*}\right)$; iqr, interquartile range.

Index parents scored more behavioural difficulties than control parents (table 3). The median total number of characteristics scored as present per index child was 8.5 (range $0-27$ ) compared with $4(0-22)$ for controls $(p=0.001)$. Index parents reported more problems in both 'health' and 'habits' sections of the questionnaire $(\mathrm{p}=0.032$ and $\mathrm{p}=0.007$ respectively). Using the recommended cut off score of 12 , nine head injured children (28\%) were considered by parental questionnaire to have a psychiatric disorder compared with two (6\%) controls $(p=0.018)$. Parents' scores were compared across the range of individual items on the test. Ten characteristics discriminated head injured from control groups: 'attacks of wheezing' $(p=0.009)$, 'temper tantrums' $(p=0.001)$, 'speech impediments' $(p=0.005)$, 'restlessness' $(p=0.023)$, 'squirmy, fidgety' $(p=0.05)$, 'frequently fights or is quarrelsome' $(p=0.003)$, 'often worries' $(p=0.005)$, 'irritable' $(p=0.003)$, 'often disobedient' $(p=0.035)$, and 'bullies other children' $(p=0.05)$. Additionally, there was a trend for head injured children to score more frequently over most of the remaining traits.

A more objective view of each child's behaviour, provided by the teachers' questionnaire, provided less discrimination between the two groups, identifying 11 (35\%) index children with behaviour disorder compared with six (21\%) controls and similar frequencies of emotional and conduct disorder. Index children none the less had significantly poorer total behavioural scores. Teachers scored head injured children significantly worse than controls on two traits from the Rutter $\mathrm{B}(2)$ scale ('squirmy, fidgety child' $(p=0.040)$ and 'often worried, worries frequently' $(p=0.050)$ ) and three from the extra Conners' items ('poor attention span' $(p=0.025)$, 'poor co-ordination' $(p=0.005)$, and 'constantly fidgeting' $(p=0.050))$. The high frequency of problems among controls reflects the classroom matching, many head injured children being in receipt of special educational provision. None the less on most individual items the head injured group showed a trend to score more frequently.

SCHOOL DATA (table 4)

Nine of 32 children (28\%) were placed in special schools at the time of follow up by questionnaire, the remainder being in a mainstream school. Four children needed support to remain within their mainstream class and two were in a special needs class within the mainstream school. Educational statements of special needs had been completed for 12 and were planned for five more children, the educational psychologist being actively involved in the management of seven. Sixteen $(48 \%)$ were coping in the normal classroom without support, although only four children (13\%) were not causing their teacher concern. Particular areas of concern varied widely (table 5), and included memory/ attentional deficits $(n=14)$, motor skills $(n=12)$, behaviour/personality problems $(n=10)$, language $(n=7)$, and cognition $(n=5)$. Three children were considered to be poor attenders at school.

Table 6 outlines specific learning problems identified by the teacher on direct questioning. Head injured children were significantly disadvantaged compared with controls in most of the areas concerning the processing of information in the classroom, despite the similarities recorded by teachers on the behavioural profile. The disinhibition, inappropriate affect, and disorientation noted frequently during early recovery from head injury appeared to have settled by the time of questioning, although the school routine still posed a problem for many children. Despite the long period of follow up for most of these children the majority had not regained their preinjury skills.

Teachers reported that there were generally enough opportunities to counsel parents of index children but that with nine of the families communication had been poor (table 5). Despitea close liaison between the head injury team,

Table 4 Educational support received by 31 index children

\begin{tabular}{lr}
\hline Placement & 9 \\
Primary & \\
With support & 1 \\
Secondary & 7 \\
With support & 3 \\
Special needs & 2 \\
Special school & 9 \\
Class size & 9 \\
$<10$ & 6 \\
$10-20$ & 16 \\
$>20$ & 12 \\
Statement of special needs & 5 \\
Current & 7 \\
Planned & \\
Educational psychologist involved &
\end{tabular}

Table 5 Teachers' subjective view of school performance and parent contact

\begin{tabular}{|c|c|c|}
\hline & $\begin{array}{l}\text { Index } \\
(n=31)\end{array}$ & $\begin{array}{l}\text { Controls } \\
(n=29)\end{array}$ \\
\hline \multicolumn{3}{|l|}{ School attendance } \\
\hline Poor & 3 & $\mathbf{0}$ \\
\hline \multicolumn{3}{|l|}{ Areas of concern } \\
\hline Any & 27 & $6(p<0.0001)$ \\
\hline Cognitive & 5 & 0 \\
\hline Language/speech & 7 & 0 \\
\hline Motor skills & 12 & 1 \\
\hline Memory/attention & 14 & 1 \\
\hline Behaviour/personality & 10 & 4 \\
\hline Other areas & 4 & 2 \\
\hline \multicolumn{3}{|l|}{ Parent contact } \\
\hline None/infrequent & 9 & 1 \\
\hline Informal/formal & 10 & 12 \\
\hline \multicolumn{3}{|l|}{ Counselling opportunities } \\
\hline None & 1 & 6 \\
\hline As needed & 5 & 9 \\
\hline Planned & 6 & 6 \\
\hline
\end{tabular}


Table 6 Educational questionnaire-teachers' observations

\begin{tabular}{|c|c|c|c|c|c|}
\hline & \multicolumn{2}{|l|}{$\begin{array}{l}\text { Index } \\
(n=31)\end{array}$} & \multicolumn{2}{|l|}{$\begin{array}{l}\text { Controls } \\
(n=29)\end{array}$} & \multirow[t]{2}{*}{$\begin{array}{l}\chi^{2} \text { test } \\
(p \text { value })\end{array}$} \\
\hline & $\begin{array}{l}\text { Applies } \\
\text { somewhat }\end{array}$ & $\begin{array}{l}\text { Applies } \\
\text { certainly }\end{array}$ & $\begin{array}{l}\text { Applies } \\
\text { somewhat }\end{array}$ & $\begin{array}{l}\text { Applies } \\
\text { certainly }\end{array}$ & \\
\hline Has problems with new tasks & 17 & 8 & 13 & 1 & 0.0075 \\
\hline Has difficulty with speeded tasks & 11 & 16 & 9 & 4 & 0.0007 \\
\hline Has problems retrieving information & 13 & 11 & 8 & 0 & 0.0001 \\
\hline Has difficulty in using appropriate word & 13 & 5 & 6 & 0 & 0.0059 \\
\hline Slow or poorly articulated speech & 14 & 7 & 5 & 0 & 0.0002 \\
\hline Has severe communication problems & 9 & 1 & 0 & 0 & 0.0036 \\
\hline Has impairment of written language skills & 10 & 10 & 3 & 1 & 0.0003 \\
\hline Has difficulties in problem solving & 11 & 12 & 12 & $\mathbf{0}$ & 0.0005 \\
\hline Appears to be losing academic ground & 10 & 6 & 3 & $\mathbf{0}$ & 0.0018 \\
\hline Uses excuses to avoid tasks & 9 & 2 & 7 & 0 & 0.060 \\
\hline Tends to get disoriented around school & 7 & 2 & 2 & 0 & 0.073 \\
\hline Tends to get disoriented in classwork & 9 & 1 & 3 & 0 & $0 \cdot 107$ \\
\hline Has problems with school routine & 10 & 1 & 2 & 1 & $0 \cdot 048$ \\
\hline May be disinhibited or show inappropriate behaviour & 7 & 4 & 4 & 2 & $0 \cdot 443$ \\
\hline Thought to have poor self image & 9 & 7 & 8 & 1 & 0.074 \\
\hline Relates well to adults & 8 & 17 & 6 & 18 & 0.849 \\
\hline \multicolumn{6}{|l|}{ May be described as } \\
\hline Careless & 9 & 6 & 9 & 1 & $0 \cdot 176$ \\
\hline Forgetful & 10 & 11 & 2 & 1 & 0.0001 \\
\hline Impulsive & 8 & 2 & 8 & 0 & $0 \cdot 379$ \\
\hline Immature & 11 & 10 & 9 & 3 & 0.060 \\
\hline
\end{tabular}

hospital school and community school, which included personal contact from at least one professional and usually an invitation to attend a team meeting, 27 teachers reported that they would have liked more support with the head injured child, 25 wanting medical and 23 educational support. Within the schools it was also felt that better medical and educational support was necessary when placing a head injured child in mainstream school. This again emphasises the problems experienced by both child and teacher in the reintegration of the head injured child into school.

\section{Discussion}

Since the inception of the head injury team, we have become increasingly aware not only of the benefits of early, structured rehabilitation in a multidisciplinary framework, but also of the continuing difficulties and special needs that head injured children have long after discharge from hospital. The poor level of provision for such children has recently been pointed out. ${ }^{36}$

Rutter and colleagues, in their detailed studies of psychiatric and cognitive sequelae of head injury in children, found a marked increase in impairment and morbidity among those who had suffered severe head injury as compared with minor head injury or non-cranial trauma. ${ }^{7-9}$ We used similar questionnaire techniques, shown to produce reliable and reproducible results, to study patients treated by the head injury team. By using classroom controls, we aimed to identify the extent to which head injury survivors suffer specific educational difficulties. Sequelae of minor head trauma have been described to overreaction by parents and disruption of normal routine. ${ }^{10} 11$ In contrast, it is known that major neuromotor impairments are common sequelae of more serious head trauma. Among adults most recovery occurs within six months of the injury ${ }^{12}$ but there are few structured data concerning children, although improvements have been observed over a five year period in one study. ${ }^{1}$ The generally optimistic view of outcome in the absence of motor impairment has recently been reviewed and challenged. ${ }^{36} \mathrm{We}$ were particularly impressed by the time taken for the return of normal behaviour and educational performance among our children, who had clear disability for many months after physical recovery. It was also clear that relatively few children had returned to their premorbid performance at school.

A major failing of this and many previous studies is the absence of firm preinjury data on which to base the above statements. Reliance is placed on parental reporting, often clouded by the stress and emotional turmoil during the acute period immediately after injury. Children who sustain major head trauma may be placed at risk because of pre-existing neurological, psychological, or social factors. Some studies which have attempted to identify premorbid characteristics of head injured patients have failed to find an excess of previous injury or behavioural problems when compared with controls, ${ }^{13}$ although others have found premorbid cognitive abilities ${ }^{9}$ and academic performance ${ }^{14}$ to be relatively poor. Brown et al found an increased incidence of premorbid psychiatric disorder in children with both minor and severe head injuries. ${ }^{8}$ There was an unsubstantiated impression that many of our children had pre-existing problems, but there are no control data to support this. Teaching staff, in our experience, are able to provide a more objective assessment of this difficult area. Future prospective data collection should include a formal educational report on each child accepted by the rehabilitation team immediately on referral, together with formal parental data obtained by questionnaire after the acute symptoms have settled.

Another compounding factor which may have enhanced the differences between cases and controls is the effect of prolonged hospitalisation per se. This may have produced social, psychological, and educational difficulties in the index children over and above that of the head injury, although Rutter and coworkers found fewer such problems in their control group of children with orthopaedic injuries. ${ }^{7-9}$ Future studies should include a further control group of 
children without head injuries who had similarly lengthy periods in hospital.

Despite these caveats it is clear from these data that major long term behavioural and cognitive sequelae are commonly encountered in children recovering from major head injury, distinct from the more obvious motor problems. Furthermore, no clinical data were able to predict this outcome and in this small series the duration of follow up did not appear to exert a significant effect. Length of coma or ventilation have been used as predictive measures with inconclusive results, ${ }^{15}$ a finding supported by the present study.

Computed tomography may be almost routine now in the presence of less severe head injury but relates poorly to outcome and should probably be reserved for those children with signs of focal intracranial lesions. ${ }^{16}$ In our patients, findings on computed tomography did not help in the assessment of prognosis for the majority of patients. Seizures, both early and late, were uncommon, and epilepsy is unlikely to have contributed significantly to the educational and behavioural problems.

Head injured children are more likely to have emotional disturbances than control children. The reasons for this observation are complex and the results of the parental behavioural assessments, in particular, must be interpreted with caution. ${ }^{17}$ Parents who have been traumatised themselves by observing their child recover from major injury will tend to overreport problems and perhaps even to engender behavioural change in the child by 'overprotection', a feature frequently noted even among parents of children suffering minor injuries. ${ }^{11}$ The significant differences among the adverse behavioural traits reported by the index parents, compared with controls, would seem to support this view (table 3) and make the differences observed by the teachers more difficult to interpret.

Of major concern is the high frequency of educational problems and the lack of information with which school personnel are briefed. In the early recovery phase children are disorientated, with a major impairment of short term memory and an inability to persist at a cognitive task for long periods. Although this appears to improve, there remain clear problems in the processing of cognitive information more than six months after the injury. At this stage, children may have no clinical neurological deficit and may be considered to have fully recovered by both doctors and family. None the less, although it has been stated that children continue to improve over long periods after the injury, ${ }^{1}$ other studies indicate that around half of a group of head injured children have not made satisfactory progress at school after 10 years. ${ }^{18}$ In our experience this continuing improvement is minimal and must not be overstated.

Children who have recovered from major head injury are not lacking in intelligence, but have subtle defects in attentional skills and memory which can be difficult to identify in the busy classroom. The remedial class may not, therefore, be the correct place for such children, unless it is the only area in which an optimal pupil-teacher ratio may be achieved. Wherever they are placed, teachers could be helped by receiving as much information as possible about the children's preinjury abilities, personality and behaviour, and perhaps by using a detailed monitoring system capable of highlighting problems relevant to head injury and showing where progress is being made. Educational policy may need to be reviewed, both to encompass some specific training for teachers about head injury, and also perhaps to change the procedure for issuing statements of special educational needs to allow for the progressive change in needs that is seen during the recovery process. It has been pointed out that head injured children have special needs but are neither sick nor mentally handicapped, and thus at presnt tend to fall in between the areas of responsibility of health and education authorities. $^{6}$

It is thus clear that there is a need for further information on the long term outcome after severe head injury in children. It is also clear that long term support continues to be essential for children who have suffered such injury.

We would like to acknowledge the contribution of Dr Peter MacFarlane, Dr Peter Stutchfield, Dr Ian Lewis, and Dr Alistair Thomson who have provided supervision since 1985, together with the many other members of staff who have comprised the head injury team.

1 Klonoff $\mathrm{H}$, Low MD, Clark C. Head injuries in children: a prospective five-year follow-up. $\mathcal{F}$ Neurol Neurosurg Psyprospective five-year fol

2 Cope DN, Hall K. Head injury rehabilitation: benefit of early intervention. Arch Phys Med Rehabil 1982;63:433-7.

3 Crouchman M. Children with head injuries. BMF 1990;301 1289-90.

4 Rutter M, Graham P, Yule A. A neuropsychiatric study in childhood. London: Heinemann Medical, 1970:240-1.

5 Conners C. Rating scales for use in drug studies in children Psychopharmacol Bull 1973;9(suppl):24-84.

6 Middleton J. Thinking about head injuries in children. f Child Psychol Psychiat 1989;30:663-70.

7 Rutter M, Chadwick O, Shaffer D, Brown G. A prospective study of children with head injuries. I. Design and methods. Psychol Med 1980;10:633-45.

8 Brown G, Chadwick O, Shaffer D, Rutter M, Traub M. A prospective study of children with head injuries. III. prospective study of children with head injuries

9 Chadwick O, Rutter M, Brown G, Shaffer D, Traub M. A prospective study of children with head injuries. II. Cognitive sequelae. Psychol Med 1981;11:49-61.

10 Farmer MY, Singer HS, Mellits ED, Hall D, Charney D. Neurobehavioural sequelae of minor head injuries in children. Pediatr Neurosci 1987;13:304-8.

11 Casey R, Ludwig S, McCormick M. Morbidity following minor head trauma in children. Pediatrics 1986;78: 497-502.

12 Braakman R, Gelpke GJ, Habbema JDF, et al. Systemic selection of prognostic features in patients with severe head injury. Neurosurgery 1980;6:362-70.

13 Klonoff $\mathrm{H}$. Head injuries in children: predisposing factors, accident conditions, accident proneness and sequelae. $A m$ Public Health 1971;61:2405-17.

14 Haas JF, Cope DN, Hall K. Premorbid prevalence of poor academic performance in severe head injury. 7 Neurol Neurosurg Psychiatry 1987;50:52-6.

15 Mahoney WJ, D'Souza BJ, Haller A, Rogers MC, Epstein MH, Freeman JM. Long-term outcome of children with severe head trauma and prolonged coma. Pediatrics 1983; 71:756-62.

16 Filley CM, Cranberg LD, Alexander MP, Hart EJ. Neurobehavioral outcome after closed head injury in childhood and adolescence. Arch Neurol 1987;44:194-8.

17 Craft AW, Shaw DA, Cartilidge NE. Head injuries in children. BMF 1972;iv:200-3.

18 Keinpeter $U$. Social integration after brain trauma during childhood. Acta Paedopsychiatr 1975;32:68-75. 